\title{
Calcific tendinitis of the rotator cuff: state of the art in diagnosis and treatment
}

\author{
Giovanni Merolla $^{1,2} \cdot$ Sanjay Singh $^{1} \cdot$ Paolo Paladini $^{1} \cdot$ Giuseppe Porcellini $^{1}$
}

Received: 31 March 2015/Accepted: 25 June 2015/Published online: 12 July 2015

(c) The Author(s) 2015. This article is published with open access at Springerlink.com

\begin{abstract}
Calcific tendinitis is a painful shoulder disorder characterised by either single or multiple deposits in the rotator cuff tendon. Although the disease subsides spontaneously in most cases, a subpopulation of patients continue to complain of pain and shoulder dysfunction and the deposits do not show any signs of resolution. Although several treatment options have been proposed, clinical results are controversial and often the indication for a given therapy remains a matter of clinician choice. Herein, we report on the current state of the art in the pathogenesis, diagnosis and treatment of calcific tendinitis of the rotator cuff.
\end{abstract}

Keywords Calcific tendinitis - Shoulder - Rotator cuff · Diagnosis · Treatment options

\section{Introduction}

Calcific tendinitis (CT) is a painful shoulder disorder characterised by either single or multiple deposits in the rotator cuff (RC) tendon or subacromial bursa [1]. It was Codman who, in his book [2], described the deposits as being in the RC tendon. The term "calcifying tendinitis"

Giovanni Merolla

giovannimerolla@hotmail.com;

giovanni.merolla@auslrn.net

1 Unit of Shoulder and Elbow Surgery, D. Cervesi Hospital, Cattolica (RN) - AUSL della Romagna Ambito Territoriale di Rimini, Italy

2 Biomechanics Laboratory "Marco Simoncelli", D. Cervesi Hospital, Cattolica (RN) - AUSL della Romagna Ambito Territoriale di Rimini, Italy was probably first coined by Plenk [3] in 1952. The disease subsides spontaneously in the majority of cases and can be managed with conservative therapy, but some patients continue to have a painful shoulder for an extended period of time with the deposits not showing any signs of resolution. New conservative treatment modalities such as ultrasound-guided needling (UGN) and extracorporeal shock wave therapy (ESWT) have emerged in recent years as additional management options. Incidence varies from 2.7 to $20 \%$, as reported by various authors $[1,4,5]$. In about $10-20 \%$ of patients, the deposits are bilateral $[1,5$, 6]. Most studies found higher incidence in women compared with men $[1,6]$. Regarding age distribution, the average age of presentation in most studies was between 30 and 50 years $[5,6]$. No deposits were found in the elderly $[5,7,8]$. Most investigators found the deposits to be more commonly located in the supraspinatus $[1,3,4,6]$, although often the deposits were also located in the infraspinatus $[1,4,6]$ and rarely in the subscapularis and teres minor [1, 4]. Most patients were sedentary workers or housewives [6]. The right shoulder was most commonly affected [6]. The natural history of the disease can be divided into three distinct clinical stages: acute, subacute and chronic. The main clinical manifestation is pain, which may or may not be associated with acute or gradual restriction of movements [4, 9]. Acute pain is often associated with the onset of the disease; however, the deposits may be asymptomatic in $20 \%$ of cases [6]. Muscle spasm, and inflammation of subacromial bursa (bursitis) and the long head of the biceps are determining symptomatic factors. The pain is, in most cases, associated with the acute phase of the disease, but episodes of acute pain are also often related to flare-ups of chronic tendinopathy or onset of rare complications not related to the evolution of the disease, such as adhesive capsulitis (AC), rotator cuff tear, 
pathology of the long head of the biceps or osteolysis of the greater tuberosity (TO) [10, 11].

\section{Aetiopathogenesis and histopathology}

The aetiopathogenesis of CT remains elusive. Codman [2] hypothesised that overuse degeneration of rotator cuff leads to calcific deposits in the tendon, and this was also supported by Bishop [12], whereas Sandstrom [13] proposed that the degeneration in the tendon follows local ischaemia which led to calcium deposition. More recently, Mohr and Bilger [14] considered that the process begins with necrosis of tenocytes due to apoptosis along with intracellular accumulation of calcium, but a more detailed description was given by Uhthoff et al. [15], who proposed that the disease goes through three stages: precalcific, calcific and postcalcific. In the precalcific stage, there is fibrocartilaginous metaplasia in the tendon; this stage is rarely symptomatic. This is followed by the calcific stage, which is further divided into formative, resting and reabsorption phases. It is in the reabsorptive phase that patients are mostly symptomatic. The postcalcific phase is the healing phase, in which there is reabsorption of the deposit. Rui et al. [16] postulated that incorrect differentiation of stem cells, tendon-derived stem cells (TDSCs), into osteoblasts or chondrocytes could be the basis of the calcification. Disorders of the thyroid (thyroxine) or oestrogen metabolism may be related to the onset of the disease. Harvie et al. [17] reported endocrine involvement in $64.7 \%$ of cases in their series, whereas Mavrikakis et al. [18] reported CT incidence in $31.8 \%$ of their diabetic patients, compared with $10.3 \%$ of the control group. Sengar et al. [19] found an increased frequency of human leucocyte antigen serotype class A1 in patients with CT. Mutation in the human homologue of the murine progressive ankylosis gene $(A N K H)$ has been reported in patients with hereditary chondrocalcinosis, leading to alteration of the picture of extracellular inorganic pyrophosphate [20]. Oliva et al. [21] found that significantly increased expression of tissue transglutaminase (tTG)2 and its substrate osteopontin was detected in calcific areas compared with levels observed in normal tissue from the same subject with calcific tendinopathy. They concluded that a variation in the expression of these genes could be characteristic of this form of tendinopathy. The correlation between increased incidence of endocrine disorders and risk of developing CT remains unclear; similarly, the associations with genetic mutations, specific antigen serotypes and expression of tissue proteins need to be understood more deeply. One may speculate that patients with the aforementioned predisposing conditions may be at greater risk of developing CT. Furthermore, in this subpopulation of subjects, abnormal pre-existing calcifications can produce or enhance a complete RC tear, requiring a surgical approach.

\section{Imaging}

\section{Conventional radiology}

Standard radiographs in anterior-posterior (AP), outlet and axillary views are used for diagnosis and follow-up of CT, because they allow localisation and assessment of the texture and morphology of the deposits [22, 23] (Fig. 1). Many authors have tried to classify the deposits in terms of size [1] or morphology [6, 24-26] (Table 1). However, the fact that there are numerous classifications indicates that no classification perfectly correlates with the radiological picture and symptomatology of the patient, and there is also significant inter-observer variability [27].

The location of the deposits in the tendons also varies [1, 22] (Table 2).

\section{Ultrasound}

Ultrasound (US) examination is a fundamental tool in diagnosis and treatment of CT [28, 29]. US has changed from having a purely diagnostic role to become an important therapeutic tool, especially for carrying out bursal lavage and tendon needling (Fig. 1b, c). Use of high-resolution US shows the presence of deposits and also defines their locations in the tendon, plus their size and texture. This technique shows RC tears in detail, and also enables staging of the deposits by correlation of shadow cones [30, 31]. In the resting phase, the deposits appear hyperechoic and arc shaped, whereas they appear non-arc shaped (fragmented/ punctate, cystic, nodular) in the resolving phase [30]. These appearances can also be correlated with the symptomatic and asymptomatic phases of the disease [32]. Farin et al. [33] divided the deposits into three types: (1) hyperechoic focus with a well-defined shadow, (2) hyperechoic focus with a faint shadow and (3) hyperechoic focus with no shadow. Doppler examination during the nodular or cystic phase shows increased vascularity around the deposits [34], which correlates well with the histopathological findings of Uhthoff et al. [35], who showed how, during the reabsorption phase, the deposits are surrounded by phagocytes and there was concomitant proliferation of vascular channels around the deposits.

\section{Magnetic resonance imaging}

Magnetic resonance imaging (MRI) is an additional but not essential imaging tool, because it does not give any additional information in most cases $[36,37]$. Calcific deposits 

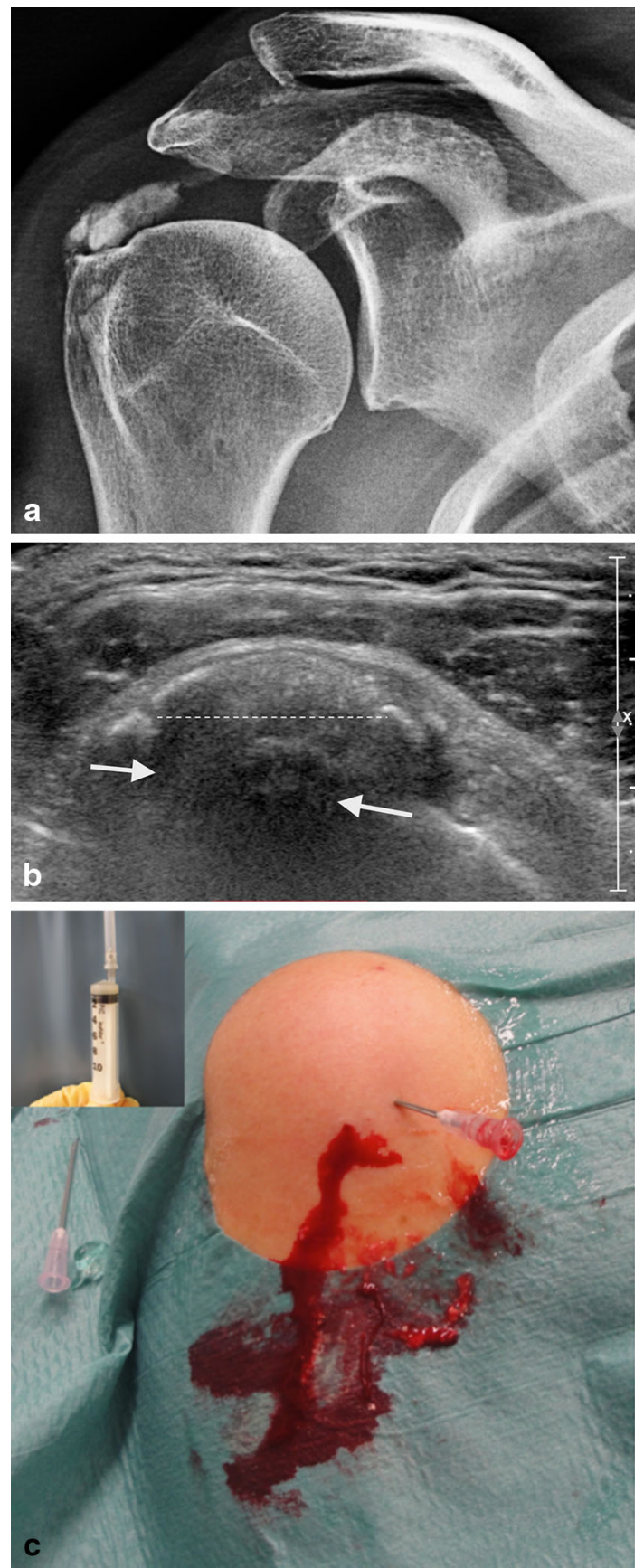

Fig. 1 A case with acute calcifying tendinitis of the rotator cuff. (a) X-ray shows a large calcium deposit $(>1.5 \mathrm{~cm})$ at the insertion of the supraspinatus tendon in touch with the greater tuberosity; (b) ultrasound image in the same patient as a demonstrates a large fragmented and punctate calcification (dotted line) with hypoechoic area indicating oedema associated with the reabsorptive phase (white arrows); (c) ultrasound-guided needling and lavage in the same case as $\mathbf{a}$ and $\mathbf{b}$ with an abundant leakage of calcium (the window on the left shows the calcium aspirated in a syringe)

have low signal intensity in all MRI sequences, although areas of increased signal intensity can be found around deposits in T2 images, signifying oedema around the deposits in the resorptive phase. Such areas of increased
Table 1 Radiographic classification of calcifying tendinitis of the shoulder

\begin{tabular}{|c|c|c|}
\hline Author & Subtype & Description \\
\hline \multirow[t]{3}{*}{ Bosworth [1] } & Small & $<0.5 \mathrm{~cm}$ \\
\hline & Medium & $0.5-1.5 \mathrm{~cm}$ \\
\hline & Large & $1.5 \mathrm{~cm}$ \\
\hline \multirow[t]{2}{*}{ DePalma et al. [7] } & Type I & $\begin{array}{l}\text { Fluffy, amorphous and ill } \\
\text { defined }\end{array}$ \\
\hline & Type II & Defined and homogeneous \\
\hline \multirow{4}{*}{$\begin{array}{l}\text { Molè et al. (French } \\
\text { Arthroscopy Association) } \\
\text { [27] }\end{array}$} & Type A & $\begin{array}{l}\text { Dense, rounded, sharply } \\
\text { delineated }\end{array}$ \\
\hline & Type B & $\begin{array}{l}\text { Multilobular, radiodense, } \\
\text { sharp }\end{array}$ \\
\hline & Type C & $\begin{array}{l}\text { Radiolucent, } \\
\text { heterogeneous, irregular } \\
\text { outline }\end{array}$ \\
\hline & Type D & $\begin{array}{l}\text { Dystrophic calcific } \\
\text { deposit }\end{array}$ \\
\hline \multirow[t]{3}{*}{ Gartner et al. [28, 29] } & Type I & Well demarcated, dense \\
\hline & Type II & $\begin{array}{l}\text { Soft contour/dense or } \\
\text { sharp/transparent }\end{array}$ \\
\hline & Type III & $\begin{array}{l}\text { Soft contour/translucent } \\
\text { and cloudy }\end{array}$ \\
\hline
\end{tabular}

Table 2 Percentage of rotator cuff tendon involvement in calcifying tendinitis of the shoulder

\begin{tabular}{ll}
\hline Tendon & Percentage $(\%)$ \\
\hline Supraspinatus & 51 \\
Infraspinatus & 44.5 \\
Teres minor & 23.3 \\
Subscapularis & 3 \\
\hline
\end{tabular}

signal intensity can be misinterpreted as a RC lesion [38, 39]. The accuracy of MRI in identifying calcific deposits is around $95 \%$, but it is more useful in cases of chronic CT, which may be associated with RC tears, AC and TO [10, 38, 40, 41] (Fig 2). All these investigations and a thorough clinical examination are of critical importance, especially when the primary disease is associated with signs and symptoms of other conditions, e.g., the stiffness occurring in the acute stage of the disease, which should be differentiated from that occurring in AC or secondary stiffness occurring in $\mathrm{RC}$ tears. Imaging must be used to differentiate chronic forms associated with TO from that occurring in association with dystrophic calcification or in tumours [42].

\section{Treatment options}

Conservative management is always the first line of treatment. This includes non-steroidal anti-inflammatory drugs (NSAIDs), physiotherapy, UGN and ESWT. The outcome 


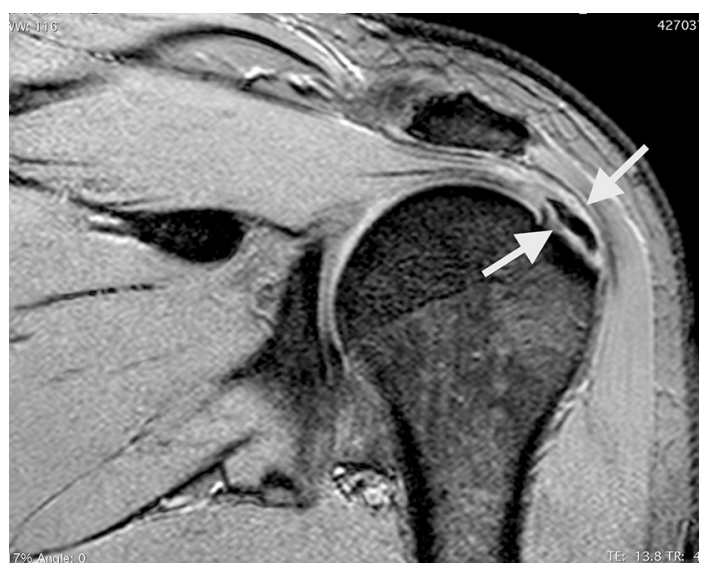

Fig. 2 Coronal fatty suppressed MRI reveals a focus of chronic calcification with associated full-thickness supraspinatus tendon tear (white arrows)

of conservative treatment was principally studied by Ogon et al. [43], who described prognostic factors whose identification was helpful for tailoring treatment for favourable outcome in the shortest possible time. They defined failure of nonoperative therapy as persistence of symptomatic calcific tendinitis of the shoulder after a minimum of 6 months of nonoperative treatment, including a minimum of 3 months of standardised nonoperative treatment. They concluded that the prognostic factors that significantly increased the probability of failure of nonoperative therapy (negative prognostic factors) were bilateral calcific deposit occurrence, localization near the anterior portion of the acromion, medial (subacromial) extension and high volume of calcific deposit. Prognostic factors that significantly reduced the probability of failure of nonoperative therapy (positive prognostic factors) were Gartner type III calcific deposit and lack of sonographic sound extinction of the calcific deposit. Treatment can be modulated depending upon the presence of these prognostic factors. Usually, the acute phase requires NSAIDs to relieve the pain and appropriate physiotherapy [passive range-of-motion (ROM) exercises] to avoid stiffness of the shoulder. Local steroid injection in the acute phase is a debatable topic, as studies have shown it to have positive [35] or no effect [44], or even a negative effect in the form of stopping reabsorption of the deposits [45]. In most cases, conservative treatment is sufficient for resolution of symptoms. Cho et al. [46] reported excellent to good results in $72 \%$ of their patients.

\section{Ultrasound-guided needling}

Although UGN was first demonstrated under fluoroscopy control by Comfort et al. [47], it was Farin et al. [33] who described use of US for bursal lavage and needling. Since then, it has been a commonly used intervention, as it is inexpensive and can be carried out on an out-patient basis under local anaesthesia (Fig. 1c). Gonzalez et al. [48] recently published a study of 121 patients with 2-year follow-up, reporting satisfactory results after UGN at 3 months. de Witte et al. [49] carried out a randomised controlled trial (RCT) between UGN with subacromial injection and subacromial injection alone; both groups showed improvement, but the UGN group fared better as compared with injection alone. A recent systemic review of literature [50] for the efficacy of UGN in CT concluded that, due to the variation in studies and the low quality of evidence, the efficacy of UGN could not be firmly established and additional high-quality studies are required.

\section{Extracorporeal shock wave therapy}

ESWT has been used for medical treatment since the 1990s. Its use for CT is increasing, and like UGN, there is a lot of disparity, regarding the dosage (energy flux density), duration (impulses) and interval of administration of ESWT.

Low-energy (below $0.08 \mathrm{~mJ} / \mathrm{mm}^{2}$ ), medium-energy $\left(0.08-0.28 \mathrm{~mJ} / \mathrm{mm}^{2}\right)$ and high-energy $\left(0.28-0.60 \mathrm{~mJ} / \mathrm{mm}^{2}\right)$ shock waves have been defined [51]. The shock waves can be generated through electrohydraulic, electromagnetic or piezoelectric mechanisms. Farr et al. [52] compared one dose of $0.3 \mathrm{~mJ} / \mathrm{mm}^{2}$ versus two doses of $0.2 \mathrm{~mJ} / \mathrm{mm}^{2}$, finding the former to be more effective. Ioppolo et al. [53] also published a RCT and found $0.20 \mathrm{~mJ} / \mathrm{mm}^{2}$ dosage to be more effective than $0.10 \mathrm{~mJ} / \mathrm{mm}^{2}$. Albert et al. [54] also found in favour of high-dose therapy, though their followup was only 3 months and they did not find any significant differences in the size of deposits on X-ray examination.

Various energy doses of ESWT have been reported for treatment of CT; most authors described good clinical outcomes with low- and medium-energy waves [51-53, 55-57]. The authors of a RCT [55] in which the control group was given sham treatment opined that the results were better in the ESWT group. The researchers also suggested other forms of treatment for patients who did not respond to ESWT after 6 months. Krasny et al. [56] compared ESWT alone and ESWT combined with UGN, finding that the combined treatment was more effective in relieving symptoms and that fewer patients in the combined treatment group required surgery. Daecke et al. [57] published long-term follow-up of patients managed with ESWT; although $20 \%$ of all patients required surgery, $70 \%$ of patients were treated successfully and no longterm complications were seen. Lee et al. [58] carried out a systematic review to determine the midterm effectiveness of ESWT, but due to the variability of treatment and reliability of the available studies, they were not able to come 

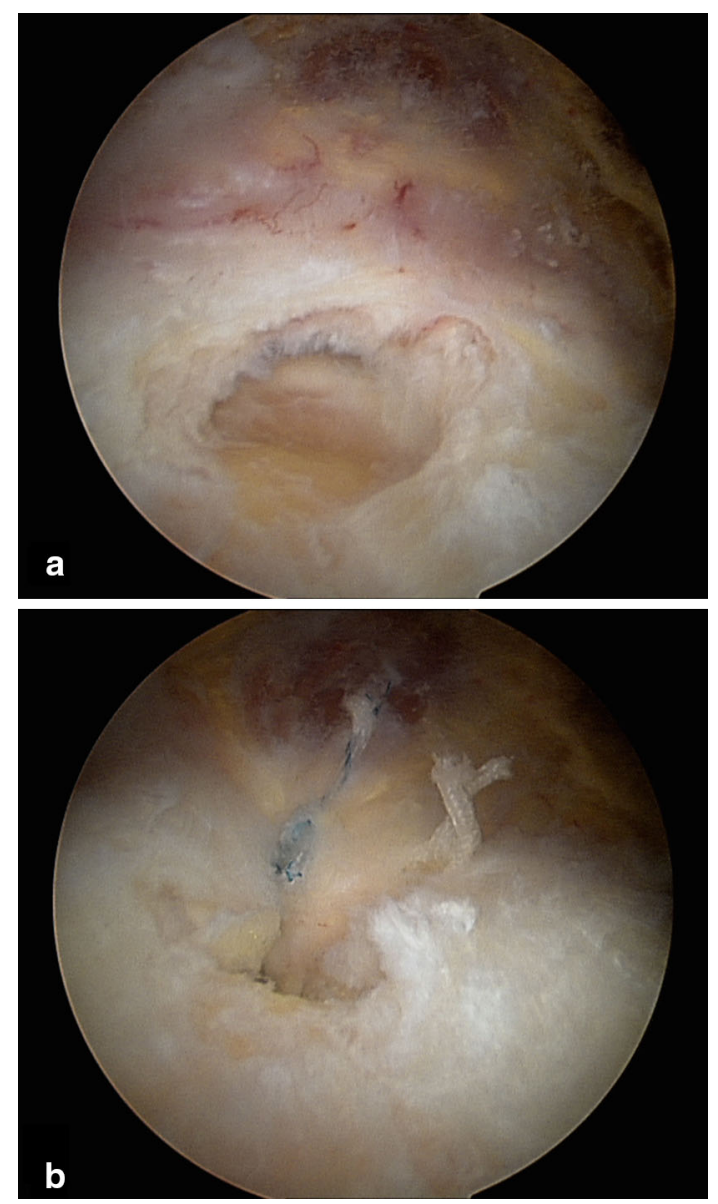

Fig. 3 (a) Arthroscopic findings shows a complete insertional supraspinatus tendon tear after complete removal of a calcium deposit; (b) supraspinatus tendon-to-bone repair with a double suture anchor at the end of the arthroscopic procedure

to a conclusion regarding a particular dosage of treatment. Kim et al. [59] carried out a comparative study between UGN and ESWT, finding better radiological and clinical outcomes in the UGN group, though both groups showed improvement relative to initial findings.

\section{Surgical treatment}

After failure of conservative treatment modalities, surgical removal of the deposits is the remaining option. Although favourable results have been described with open removal of calcific deposits [4, 60-62], arthroscopy has become the preferred technique to treat the chronic formative phase of $\mathrm{CT}$, offering results similar to open surgery but with less morbidity of the deltoid [63-69] (Fig. 3a, b). However, many issues remain under debate, such as repairing versus leaving the defect created, complete versus incomplete removal of the deposits and removal of deposits versus only acromioplasty. Ark et al. [64] published a report of 23 patients suggesting that complete removal of the deposits is not essential; they also did not attempt repair of the defects created following the removal of deposits. Other researchers $[65,66]$ have also made similar suggestions. In their study, Jerosch et al. [67] concluded that repair is not required following removal of the deposits, but they insisted on complete removal of the deposits. In contrast, Porcellini et al. [68] recommended complete removal of deposits followed by repair of the defect in the tendon, using simple side-to-side sutures or suture anchors depending upon the size of the residual defect. They argued that repair gives similar results without the fear of propagation of the tear and also helps in early patient rehabilitation. Tillander et al. [69] compared the outcome of acromioplasty in 50 patients: 25 with CT and another 25 with other causes of impingement syndrome. They did not find any significant difference between the Constant scores of the two groups at 2 years and recommended that the deposits should be left alone. However, other authors [6468] recommended acromioplasty only in cases of visible mechanical impingement during arthroscopy, characterised by roughening of the ligament and osteophytes on the undersurface of the ligaments, as it did not have any additional benefit and the number of cases requiring acromioplasty varied in each of the studies.

Most authors [64-66, 68] recommended informing the patient about delayed recovery post-surgery and were of the opinion that surgical treatment should be reserved for patients not responding to conservative treatment for more than 6 months.

\section{Complications}

In a recent review, Merolla et al. [11] described various complications associated with CT. They categorised pain as a complication, as the majority of patients with CT are asymptomatic. Other complications in their study were secondary AC and RC tears, both of which could occur during the primary disease or post-surgical intervention. They also pointed out ossifying tendinitis, which is an extremely rare condition occurring following surgical removal of calcium deposits. Many authors [10, 11, 38, 40, 41] have described $\mathrm{TO}$ of the greater tuberosity as an occurrence along with CT of the RC. Porcellini et al. [10] suggested that TO should be identified as a different form of CT which is prone to delayed recovery of patients managed conservatively and surgically. During UGN, mild vasovagal syncope may occur. High-dose ESWT is associated with pain sometimes requiring local anaesthesia, and local haematoma, erythema and ecchymosis have also been reported. Osteonecrosis of the humeral head has also been described [70]. 


\section{Overview}

$\mathrm{CT}$ of the RC is a controversial topic with several treatment options that depend on the biologic stage of the disease. Although reabsorption occurs spontaneously in the majority of cases, a subpopulation of patients with persistent painful shoulder require conservative or operative management. In addition, some complications such as TO, AC or ossifying tendinitis (very rare) may give rise to prolonged pain resistant to common conservative therapies. UGN is indicated in the acute phase, but good results have also been found in patients with chronic calcific deposits. ESWT can be reasonably used in chronic calcific cases, even in combination with UGN. Surgical treatment should be considered when conservative measures have failed or in cases with US or MRI evidence of RC tears.

Open Access This article is distributed under the terms of the Creative Commons Attribution 4.0 International License (http://crea tivecommons.org/licenses/by/4.0/), which permits unrestricted use, distribution, and reproduction in any medium, provided you give appropriate credit to the original author(s) and the source, provide a link to the Creative Commons license, and indicate if changes were made.

\section{References}

1. Bosworth BM (1941) Calcium deposits in the shoulder and subacromial bursitis: a survey of 12122 shoulders. JAMA 116:2477-2482

2. Codman EA (1934) The shoulder. Thomas Todd, Boston

3. Plenk HP (1952) Calcifying tendinitis of the shoulder. Radiology 59:384-389

4. Bosworth BM (1941) Examination of the shoulder for calcium deposits. Technique of fluoroscopy and spot film roentgenography. J Bone Jt Surg 23:567-577

5. Welfling J, Kahn MF, Desroy M, Paolaggi JB, de Sèze S (1965) Calcifications of the shoulder. II. The disease of multiple tendinous calcifications. Rev Rhum Mal Osteoartic 32(6):325-334

6. DePalma AF, Kruper JS (1961) Long term study of shoulder joints afflicted and treated for calcific tendinitis. Clin Orthop 20:61-72

7. Lippmann RK (1961) Observations concerning the calcific cuff deposit. Clin Orthop 20:49-60

8. McLaughlin HL (1946) Lesions of the musculotendinous cuff of the shoulder: III. Observations on the pathology, course and treatment of calcific deposits. Ann Surg 124(2):354-362

9. McKendry RJ, Uhthoff HK, Sarkar K, Hyslop PS (1982) Calcifying tendinitis of the shoulder: prognostic value of clinical, histologic, and radiologic features in 57 surgically treated cases. J Rheumatol 9(1):75-80

10. Porcellini G, Paladini P, Campi F, Pegreffi F (2009) Osteolytic lesion of greater tuberosity in calcific tendinitis of the shoulder. J Shoulder Elbow Surg 18(2):210-215. doi:10.1016/j.jse.2008.09.016

11. Merolla G, Bhat MG, Paladini P, Porcellini G (2015) Complications of calcific tendinitis of the shoulder: a concise review. J Orthop Traumatol [Epub ahead of print]

12. Bishop WA Jr (1938) Calcification of the supraspinatus tendon: cause, pathologic picture and relation to the scalenus anticus syndrome. Arch Surg 39:231-246
13. Sandstrom C (1938) Peridentinis calcarea: common disease of middle life. Its diagnosis, pathology and treatment. Am J Roentgenol 40:1-21

14. Mohr W, Bilger S (1990) Basic morphologic structures of calcified tendinopathy and their significance for pathogenesis. Z Rheumatol 49(6):346-355

15. Uhthoff HK, Loehr JW (1997) Calcific tendinopathy of the rotator cuff: pathogenesis, diagnosis, and management. J Am Acad Orthop Surg 5:183-191

16. Rui YF, Lui PP, Chan LS, Chan KM, Fu SC, Li G (2011) Does erroneous differentiation of tendon-derived stem cells contribute to the pathogenesis of calcifying tendinopathy? Chin Med J (Engl) 124(4):606-610

17. Harvie P, Pollard TC, Carr AJ (2007) Calcific tendinitis: natural history and association with endocrine disorders. J Shoulder Elbow Surg 16(2):169-173

18. Mavrikakis ME, Drimis S, Kontoyannis DA, Rasidakis A, Moulopoulou ES, Kontoyannis S (1989) Calcific shoulder periarthritis (tendinitis) in adult onset diabetes mellitus: a controlled study. Ann Rheum Dis 48(3):211-214

19. Sengar DP, McKendry RJ, Uhthoff HK (1987) Increased frequency of HLA-A1 in calcifying tendinitis. Tissue Antigens 29(3):173-174

20. Zhang Y, Johnson K, Russell RG, Wordsworth BP, Carr AJ, Terkeltaub RA, Brown MA (2005) Association of sporadic chondrocalcinosis with a -4-basepair G-to-A transition in the $5^{\prime}$ untranslated region of ANKH that promotes enhanced expression of ANKH protein and excess generation of extracellular inorganic pyrophosphate. Arthritis Rheum 52(4):1110-1117

21. Oliva F, Barisani D, Grasso A, Maffulli N (2011) Gene expression analysis in calcific tendinopathy of the rotator cuff. Eur Cell Mater 21:548-557

22. Farin PU (1996) Consistency of rotator-cuff calcifications. Observations on plain radiography, sonography, computed tomography, and at needle treatment. Invest Radiol 31(5):300-304

23. Gosens T, Hofstee DJ (2009) Calcifying tendinitis of the shoulder: advances in imaging and management. Curr Rheumatol Rep 11(2):129-134

24. Molé D, Kempf JF, Gleyze P, Rio B, Bonnomet F, Walch G (1993) Results of endoscopic treatment of non-broken tendinopathies of the rotator cuff. Calcifications of the rotator cuff [in French]. Rev Chir Orthop 79:532-541

25. Gartner J, Heyer A (1995) Calcific tendinitis of the shoulder. Orthopäde 24(3):284-302

26. Gartner J, Simons B (1990) Analysis of calcific deposits in calcifying tendinitis. Clin Orthop 254:111-120

27. Maier M, Schmidt-Ramsin J, Glaser C, Kunz A, Küchenhoff H, Tischer T (2008) Intra- and interobserver reliability of classification scores in calcific tendinitis using plain radiographs and CT scans. Acta Orthop Belg 74(5):590-595

28. Farin PU, Räsänen H, Jaroma H, Harju A (1996) Rotator cuff calcifications: treatment with ultrasound-guided percutaneous needle aspiration and lavage. Skeletal Radiol 25(6):551-554

29. Papatheodorou A, Ellinas P, Takis F, Tsanis A, Maris I, Batakis $N$ (2006) US of the shoulder: rotator cuff and non-rotator cuff disorders. Radiographics 26(1):e23

30. Lin CH, Chao HL, Chiou HJ (2012) Calcified plaque resorptive status as determined by high-resolution ultrasound is predictive of successful conservative management of calcific tendinosis. Eur $\mathbf{J}$ Radiol 81(8):1776-1781. doi:10.1016/j.ejrad.2011.05.018

31. Chiou HJ, Chou YH, Wu JJ, Hsu CC, Huang DY, Chang CY (2002) Evaluation of calcific tendonitis of the rotator cuff: role of color Doppler ultrasonography. J Ultrasound Med 21(3):289-295

32. Le Goff B, Berthelot JM, Guillot P, Glémarec J, Maugars Y (2010) Assessment of calcific tendonitis of rotator cuff by 
ultrasonography: comparison between symptomatic and asymptomatic shoulders. Jt Bone Spine 77(3):258-263. doi:10.1016/j. jbspin.2010.01.012

33. Farin PU, Jaroma H, Soimakallio S (1995) Rotator cuff calcifications: treatment with US-guided technique. Radiology 195(3):841-843

34. Chiou HJ, Chou YH, Wu JJ, Huang TF, Ma HL, Hsu CC, Chang CY (2001) The role of high resolution ultrasonography in management of calcific tendonitis of the rotator cuff. Ultrasound Med Biol 27(6):735-743

35. Uhthoff H, Sarkar K, Maynard J (1976) Calcifying tendinitis: a new concept of its pathogenesis. Clin Orthop Relat Res 118:164-168

36. Loew M, Sabo D, Wehrle M, Mau H (1996) Relationship between calcifying tendinitis and subacromial impingement: a prospective radiography and magnetic resonance imaging study. J Shoulder Elbow Surg 5(4):314-319

37. Zubler C, Mengiardi B, Schmid MR, Hodler J, Jost B, Pfirrmann CW (2007) MR arthrography in calcific tendinitis of the shoulder: diagnostic performance and pitfalls. Eur Radiol 17(6):1603-1610

38. Bachmann GF, Melzer CH, Heinrics CM, Möhring B, Rominger MB (1997) Diagnosis of rotator cuff lesions: comparison of US and MRI on 38 joint specimens. Eur Radiol 7(2):192-197

39. Rutten MJ, Jager GJ, Blickman JG (2006) From the RSNA refresher courses: US of the rotator cuff: pitfalls, limitations and artifacts. Radiographics 26(2):589-604

40. Maier M, Stäbler A, Schmitz C, Lienemann A, Köhler S, Dürr HR, Pfahler M, Refior HJ (2001) On the impact of calcified deposits within the rotator cuff tendons in shoulders of patients with shoulder pain and dysfunction. Arch Orthop Trauma Surg 121(7):371-378

41. Chan R, Kim D, Millet P, Weissman BN (2004) Calcifying tendinitis of rotator cuff with cortical bone erosion. Skeletal Radiol 33(10):596-599

42. Brown KT, Kattapuram SV, Rosentahl DI (1986) Computed tomography analysis of bone tumors: patterns of cortical destruction and soft tissue extension. Skeletal Radiol 15(6):448-451

43. Ogon P, Suedkamp NP, Jaeger M, Izadpanah K, Koestler W, Maier D (2009) Prognostic factors in nonoperative therapy for chronic symptomatic calcific tendinitis of the shoulder. Arthritis Rheum 60(10):2978-2984. doi:10.1002/art.24845

44. Noel E, Carillon Y, Gaillard T, Bouvier M (1997) Needle aspiration irrigation in calcifying tendinitis of rotator cuff. In: Gazielly DF, Gleyze PT (eds) The cuff. Elsevier, Paris, pp $152-157$

45. Tillander B, Franzen LE, Karlsson MH, Norlin R (1999) Effect of steroid injections on the rotator cuff: an experimental study in rats. J Shoulder Elbow Surg 8(3):271-274

46. Cho NS, Lee BG, Rhee YG (2010) Radiologic course of the calcific deposits in calcific tendinitis of the shoulder: does the initial radiologic aspect affect the final results? J Shoulder Elbow Surg 19(2):267-272. doi:10.1016/j.jse.2009.07.008

47. Comfort TH, Arafiles R (1978) Barbotage of the shoulder with image-intensified fluoroscopic control of needle placement for calcified tendinitis. Clin Orthop Relat Res 135:171-178

48. Castillo-González FD, Ramos-Álvarez JJ, Rodríguez-Fabián G, González-Pérez J, Calderón-Montero J (2014) Treatment of the calcific tendinopathy of the rotator cuff by ultrasound-guided percutaneous needle lavage. Two years prospective study. Muscles Ligaments Tendons J 4(2):220-225

49. de Witte PB, Selten JW, Navas A, Nagels J, Visser CP, Nelissen RG, Reijnierse M (2013) Calcific tendinitis of the rotator cuff: a randomized controlled trial of ultrasound-guided needling and lavage versus subacromial corticosteroids. Am J Sports Med 41(7):1665-1673. doi:10.1177/0363546513487066
50. Vignesh KN, McDowall A, Simunovic N, Bhandari M, Choudur HN (2015) Efficacy of ultrasound-guided percutaneous needle treatment of calcific tendinitis. AJR Am J Roentgenol 204(1):148-152. doi:10.2214/AJR.13.11935

51. Rompe JD, Kirkpatrick CJ, Kullmer K, Schwitalle M, Krischek O (1998) Dose-related effects of shock waves on rabbit tendo Achillis: a sonographic and histological study. J Bone Jt Surg Br 80(3):546-552

52. Farr S, Sevelda F, Mader P, Graf A, Petje G, Sabeti-Aschraf M (2011) Extracorporeal shockwave therapy in calcifying tendinitis of the shoulder. Knee Surg Sports Traumatol Arthrosc 19(12):2085-2089. doi:10.1007/s00167-011-1479-z

53. Ioppolo F, Tattoli M, Di Sante L, Attanasi C, Venditto T, Servidio M, Cacchio A, Santilli V (2012) Extracorporeal shock-wave therapy for supraspinatus calcifying tendinitis: a randomized clinical trial comparing two different energy levels. Phys Ther 92(11):1376-1385. doi:10.2522/ptj.20110252

54. Albert JD, Meadeb J, Guggenbuhl P, Marin F, Benkalfate T, Thomazeau H, Chalès G (2007) High-energy extracorporeal shock-wave therapy for calcifying tendinitis of the rotator cuff: a randomised trial. J Bone Jt Surg Br 89(3):335-341

55. Hsu CJ, Wang DY, Tseng KF, Fong YC, Hsu HC, Jim YF (2008) Extracorporeal shock wave therapy for calcifying tendinitis of the shoulder. J Shoulder Elbow Surg Br 17(1):55-59

56. Krasny C, Enenkel M, Aigner N, Wlk M, Landsiedl F (2005) Ultrasound-guided needling combined with shock-wave therapy for the treatment of calcifying tendonitis of the shoulder. J Bone Jt Surg Br 87(4):501-507

57. Daecke W, Kusnierczak D, Loew M (2002) Long-term effects of extracorporeal shockwave therapy in chronic calcific tendinitis of the shoulder. J Shoulder Elbow Surg 11(5):476-480

58. Lee SY, Cheng B, Grimmer-Somers K (2011) The midterm effectiveness of extracorporeal shockwave therapy in the management of chronic calcific shoulder tendinitis. J Shoulder Elbow Surg 20(5):845-854. doi:10.1016/j.jse.2010.10.024

59. Kim YS, Lee HJ, Kim YV, Kong CG (2014) Which method is more effective in treatment of calcific tendinitis in the shoulder? Prospective randomized comparison between ultrasound-guided needling and extracorporeal shock wave therapy. J Shoulder Elbow Surg 23(11):1640-1646. doi:10.1016/j.jse.2014.06.036

60. Harmon PH (1958) Methods and results in the treatment of 2580 painful shoulders with special reference to calcific tendinitis and the frozen shoulder. Am J Surg 95:527-544

61. McLaughlin HL (1963) The selection of calcium deposits for operation: the technique and resultant operations. Surg Clin N Am 43:1501-1504

62. Rochwerger A, Franceschi JP, Viton JM, Roux H, Mattei JP (1999) Surgical management of calcific tendinitis of the shoulder: an analysis of 26 cases. Clin Rheumatol 18(4):313-316

63. Rubenthaler F, Ludwig J, Wiese M, Wittenberg RH (2003) Prospective randomized surgical treatments for calcifying tendinopathy. Clin Orthop Relat Res 410:278-284

64. Ark JW, Flock TJ, Flatow EL, Bigliani LU (1992) Arthroscopic treatment of calcific tendinitis of the shoulder. Arthroscopy 8(2):183-188

65. Seil R, Litzenburger H, Kohn D, Rupp S (2006) Arthroscopic treatment of chronically painful calcifying tendinitis of the supraspinatus tendon. Arthroscopy 22(5):521-527

66. Balke M, Bielefeld R, Schmidt C, Dedy N, Liem D (2012) Calcifying tendinitis of the shoulder: midterm results after arthroscopic treatment. Am J Sports Med 40(3):657-661. doi:10.1177/ 0363546511430202

67. Jerosch J, Strauss JM, Schmiel S (1998) Arthroscopic treatment of calcific tendinitis of the shoulder. J Shoulder Elbow Surg $7(1): 30-37$ 
68. Porcellini G, Paladini P, Campi F, Paganelli M (2004) Arthroscopic treatment of calcifying tendinitis of the shoulder: clinical and ultrasonographic follow-up findings at two to five years. J Shoulder Elbow Surg 13(5):503-508

69. Tillander BM, Norlin RO (1998) Change of calcifications after arthroscopic subacromial decompression. J Shoulder Elbow Surg 7(3):213-217
70. Durst HB, Blatter G, Kuster MS (2002) Osteonecrosis of the humeral head after extracorporeal shock-wave lithotripsy. J Bone Jt Surg Br 84(5):744-746 